\title{
Normas de convivência escolar: uma avaliação sob o olhar de alunos do Ensino Médio do CAp-UFRJ
}

\author{
Lúcia Regina Goulart Vilarinho ${ }^{1}$ \\ Maria Beatriz Porciuncula Porangaba Costa ${ }^{2}$
}

\begin{abstract}
RESUMO
Disciplina escolar é uma questão complexa e para alcançá-la é necessário ter consciência desse saber para a vida e para a construção da sociedade. Este artigo apresenta uma avaliação, conduzida na perspectiva de alunos, das normas de convivência escolar aplicadas em uma escola de Educação Básica, localizada na cidade do Rio de Janeiro. Foi utilizada a Abordagem dos Participantes, tendo-se contato com 41 alunos que responderam a três questionários, emitindo suas percepções sobre a atualidade/importância dessas normas. A análise dos dados obtidos revelou que apesar das normas estarem em funcionamento há mais de 10 anos, elas ainda estão atuais para os alunos. Para a grande maioria dos respondentes as normas são importantes na construção de comportamentos favoráveis à aprendizagem. As respostas evidenciaram coerência e as reclamações, muitas delas, procedentes, devem ser repensadas pela escola. No computo geral, expressaram um sentimento de orgulho por pertencerem ao corpo discente do colégio.
\end{abstract}

PALAVRAS-CHAVE: Avaliação. Normas de convivência escolar. Ensino Médio. Abordagem dos Participantes.

School Behavior Standards: an evaluation in the perspective of the high school students of the Application School of the Federal University of Rio de Janeiro

\footnotetext{
${ }^{1}$ Doutora em Educação pelaUFRJ, Atua na Fundação Cesgranrio - Rio de Janeiro, RJ, Brasil. https://orcid.org/00000002-1246-6049.lgvilarinho@netbotanic.com.br.

${ }^{2}$ Especialista em Psicopedagogia, Atua na Universidade Federal do Rio de Janeiro- Colégio de Aplicação - Rio de Janeiro, RJ, Brasil. https://orcid.org/0000-0002-5491-4268.mbppc@uol.com.br.
} 


\begin{abstract}
School discipline is a complex question and to achieve it, it is necessary to be aware of its importance for life and the construction of society. This article presents an evaluation conducted in the students' perspective on the school behavior standards applied in a basic education school in the city of Rio de Janeiro. The study used the Participant Approach, by contacting 41 students whom responded three questionnaires and emitted their perceptions about the actuality/importance of these standards. The data analysis obtained revealed that although the standards have been in place for over 10 years, they are still current to the students. The greater part of the respondents consider that the standards are important for the construction of behaviors conducive to learning. The responses demonstrated coherence and the complaints, many of which are proceeding, should be reconsidered by the school. Overall, the participants expressed a sense of pride in being part of the school's student body.
\end{abstract}

KEYWORDS: Evaluation. School behavior standards. High school. Participant centered approach.

\title{
Normas de convivência escolar: construção da autonomia ou dominação?
}

Indisciplina e violência são dois problemas que interferem na vida escolar e que, muitas vezes, ocorrem por ausência ou descumprimento de normas de conduta previamente estabelecidas, sejam elas resultado de discussões entre professores ou que mesclem a experiência docente e os desejos e/ou necessidades dos alunos. A falta de mecanismos eficazes para a resolução desses problemas gera insatisfação e angústia entre os profissionais de ensino, levando-os a se sentirem despreparados para mediar os conflitos (LEITE, 2008)

Aquino (1996) já afirmava, no final do século passado, que os conflitos não são mais algo esporádico e particular. Na realidade, tornaram-se um 
dos maiores obstáculos às atividades pedagógicas da escola. Esse mesmo autor alerta que não é tarefa do professor resolver os problemas através de "receitas prontas"; ele deve sim criar, considerando o seu contexto de trabalho e o que ensina, um método que ajude o desenvolvimento da aprendizagem, minimizando os problemas de disciplina na sala de aula. Em uma perspectiva mais ampla, Nóvoa (2008) afirma que se colocou sobre os ombros dos professores a responsabilidade pela educação de aspectos que, tradicionalmente, pertenciam à comunidade e à família. Assim esse profissional, que se formou para ensinar conteúdos científicos e acadêmicos, vê-se praticamente obrigado a transmitir valores e atitudes relacionados à convivência social e à cidadania. Ainda que o professor não possa deixar de fazer comentários sobre o aprendizado de tais condutas, esse não é o seu ofício principal, cabendo à escola transmitir às novas gerações as bases do arcabouço cultural de nossa civilização.

Existe, no entanto, outra perspectiva que situa a disciplina em uma perspectiva mais abrangente e afirma não ser uma formação trazida de casa; ela é aprendida, sendo de interesse geral porque facilita a relação das pessoas. A disciplina na escola é uma conquista do saber, constituindo-se em tarefa difícil, árdua e complexa. Para alcançá-la, é importante ter consciência desse saber para a vida e para a construção da sociedade (MACEDO, 2005).

No rastro desses pensamentos, pode-se pensar na indisciplina como força de resistência ao processo educativo da escola, ou como elemento de uma crise que pede mudanças em relação ao que é praticado no contexto educacional. Segundo essa leitura, a indisciplina seria uma espécie de tensão, solicitando à escola mudanças em relação ao potencial de seus recursos. Assim, cabe questionar se as escolas estão cultivando visões capazes de enfrentar os principais desafios do mundo contemporâneo. (GARCIA, 2009).

A disciplina é fundamental no desenvolvimento de qualquer atividade, seja ela realizada em grupo ou individualmente. Há que se ter 
ordem para se processar a atividade. O comportamento disciplinado não pode ser percebido como padronizado, inflexível, rígido; mas a disciplina exclusivamente "regulamentadora" limita ou impede a criatividade. Em contrapartida, quando nenhuma norma é atendida, permitindo-se que cada uma faça a atividade a sua maneira, seguramente esse será o caminho mais indicado em direção ao caos. (CARVALHO, 1996).

Sabe-se que as escolas não são instituições neutras, pois ao terem como finalidade precípua o ensino de habilidades e conteúdos trazem em suas falas mensagens ideológicas, discursos pedagógicos e relações de poder que produzem e reproduzem a consciência e a identidade das pessoas existentes na sociedade como um todo. (BERNSTEIN, 1996). Mas, essas mesmas escolas podem contribuir para a transformação social quando se propõem a avaliar aquilo que está em prática no seu dia a dia.

Ainda que existam muitos motivos que levem à indisciplina, a escola precisa realizar a contento o seu processo de aprendizagem. É necessário que a sala de aula seja marcada por comportamentos educados, que permitam um convívio pacífico entre os alunos e entre eles e o professor.

Sem questionar as causas da desobediência ou repúdio às normas de convivência e tendo como 'pano de fundo' a perspectiva de disciplina como tarefa construtiva da escola, este estudo se projetou para avaliar a atualidade das normas aplicadas em uma escola de Ensino Fundamental e Médio. Nesta direção, foi relevante saber como os alunos percebem essas normas e, em última instância, se elas interferem ou não em suas aprendizagens.

\section{Revisão teórica}

\section{Uniformes escolares: conforto, praticidade e originalidade}

Os uniformes são um tipo de farda, um vestuário padronizado, usado em uma instituição, classe ou corporação, com o objetivo de tornar, quem o usa, semelhante ou idêntico (CORAZZA, 2004). 
Tal vestimenta surge por volta do século XV com o exército, uma das primeiras organizações a se utilizar desse tipo de indumentária, sendo usado de forma igual por todos os militares, independentemente de sua patente. Mais tarde, vão ser usados em hospitais, hospícios e asilos (SILVA, 2007).

Para Silva e Catani (2016), os uniformes pertencem à cultura de uma instituição, eles fazem as marcas de um lugar nos indivíduos. Segundo essas autoras, os uniformes se caracterizam por sua praticidade, estando também relacionados com a tradição, pois em algum local de tal indumentária é colocada a insígnia da instituição a qual pertence. Eles são parte de uma simbologia que permeia as instituições educativas, significando valores, normas e intenções que dão contorno à relação pedagógica sem que seja necessário o discurso verbal.

O vestuário, de modo geral, transmite intrinsecamente aspectos culturais da sociedade na qual se insere. Para Eco (1989), a roupa não serve apenas para cobrir o corpo, segundo o frio ou o calor, ela deve ser vista como uma forma de inventar a comunicação, trazendo consigo a noção de comunicabilidade em uma sociedade onde tudo é informação. Assim, o vestuário traz a ideia de entendimento e amplitude da vida em sociedade.

Com todas as modificações que possam ter sofrido ao longo dos anos, os uniformes representam a identificação de um grupo e, muitas vezes, a sua diferenciação de status. Também representam o controle e a padronização de indivíduos. Existem aqueles que defendem o uniforme como forma de segurança e outros que afirmam que é um receptor de diferenças sociais. De qualquer modo, seja na escola ou em outro local, é por meio do uniforme que se pode ter uma ideia da cultura institucional que perpassa a história do seu uso (BORGES, 2015).

O uso do uniforme escolar, no Brasil, se dá a partir de inícios do século passado. Surge articulado à ideia de democracia, de igualdade representada pela estética das roupas, ou à falta de democracia por dificuldades impostas pelas condições materiais que obrigavam à aquisição 
do traje (SILVA, 2007). Acompanha a infância e a adolescência, materializando essa situação e permanecem na memória dos alunos dos tempos de escola.

Mesmo sendo um elemento de padronização, não se pode deixar de ver o uniforme desconectado da estrutura social mais ampla onde se insere. Hoje ele é visto como um elemento de identificação/diferenciação. Essa dicotomia é observada quando se analisa a maneira como os jovens usam o uniforme e os significados que a ele atribuem, sendo pouco provável que percebam a estratégia de regulação e disciplinamento que se escondia sob o seu uso.

Atualmente percebe-se a tendência de as meninas usarem camisetas curtas e mais apertadas, muitas delas deixam parte do abdômen à vista para chamar atenção sobre sua forma física. Esse modo de usar o uniforme vem ao encontro da tendência do novo século, que é a do culto ao corpo. Nessa dimensão, parece que a aceitação da roupa padronizada pressupõe a possibilidade de mudança do modelo convencionado como sendo o correto. Tudo indica que "desejar a existência do uniforme, significa a possibilidade de destacar-se no grupo e ser notada como alguém de elevada criatividade, espírito de rebeldia, sintonia com a moda, quando altera o original". (SCHEMES; SILVA; ARAÚJO, 2013, p. 55).

No caso dos meninos, o que marca é o uso de

tamanhos maiores do que seria necessário, tanto no que diz respeito à camiseta, quanto ao casaco e à calça. Toda a roupa é folgada, lembrando o costume que se vê em determinados grupos, como praticantes de skate e rappers". (SCHEMES; SILVA; ARAÚJO, 2013, p. 56).

É provável que eles usem roupas folgadas para esconder o próprio corpo, que ainda não alcançou o tamanho ideal. Schemes, Silva e Araújo (2013) dizem que, sendo a adolescência um período de intensas modificações, 
torna- se comum o aparecimento de uma insegurança quanto às suas formas físicas.

Assim, pode-se afirmar que "os alunos reconhecem a importância do uso do uniforme, mas imprimem nesse traje características pessoais, relacionadas às tendências atuais de moda". (SCHEMES; SILVA; ARAÚJO, 2013, p. 55).

Lonza (2005) afirma que os jovens não desejam mais vestirem-se como os seus pais e que o surgimento da calça jeans fez uma mutação, obrigando as escolas a aceitarem-na como seu uniforme. Outra tendência foi o uso da camiseta de algodão, atendendo à lógica da indústria nacional. Ainda de acordo com Borges (2015, p. 328), "a partir do século XXI a prioridade é o conforto e a praticidade de uma estética jovem e bonita. Os novos tempos dialogam com a população juvenil, objetivando modelos culturais e consumidores culturais".

\section{Horário escolar e normas disciplinares: uma garantia para a convivência escolar}

O horário escolar serve, fundamentalmente, para marcar o começo e o fim das atividades escolares. O tempo de aula é regulamentado em lei e a presença (ou ausência) do aluno, assim como seus atrasos, devem ser anotados e comunicados aos responsáveis (Artigo 12 da Lei no 9394 BRASIL, 1996)

São diversas as justificativas apresentadas pelos alunos para seus atrasos, especialmente para o primeiro tempo de aula: o trânsito congestionado, o despertador que não tocou, o celular que estava sem bateria, a mãe que se atrasou para acordá-lo. Muitas vezes os responsáveis desculpam os filhos, pensando que podem justificar faltas ou atrasos. Esquecem que a pontualidade é aspecto relacionado à responsabilidade necessária ao cultivo de um bom rendimento acadêmico. Esquecem, também, que a escola não pode negligenciar em relação a faltas e atrasos, 
porque cada aluno que chega atrasado à sala de aula prejudica a si e aos seus colegas.

Ensinar aos filhos a serem pontuais é dever dos pais desde a préescola. A pontualidade é uma atitude de respeito a colegas e professores que estão em sala de aula dando prosseguimento aos estudos. $\mathrm{O}$ aluno impontual perde a sua produtividade, perturba o fluxo de seus trabalhos, além de passar uma imagem de negligência.

Complementando as disposições referentes ao horário situa-se o cumprimento das regras disciplinares, também chamadas de "normas de convivência escolar”. Somente quando essas normas são cumpridas, é que o trabalho do professor pode ser executado de maneira eficiente, contribuindo para o aperfeiçoamento do rendimento do aluno.

Apesar das inúmeras mudanças que vêm ocorrendo na escola, o conceito de disciplina continua fortemente ligado à noção de controle da conduta e, para tanto, a escola usa diversos instrumentos, entre eles a avaliação educacional. De um modo geral, a indisciplina faz parte da vida escolar, sendo fonte de estresse nas relações entre professores e alunos. Um olhar mais apurado sobre as formas de indisciplina vivenciadas pode revelar que a escola precisa avançar pedagógica e institucionalmente. A indisciplina representa a incongruência entre os critérios e as expectativas definidos pela escola e o que demonstram alunos em termos sociais, afetivos e cognitivos. Ela surge como uma negação da disciplina: o aluno tem conhecimento dos seus direitos, mas nem sempre se mostra atento em relação a seus deveres, ao respeito e ao conjunto mínimo de normas de relações interpessoais.

A escola é local fundamental para a socialização dos jovens. É nela que se aprende a viver em grupo, recebendo bens culturais como a leitura, a escrita e as normas de conduta da instituição.

Crianças e jovens só aprendem a pensar e a viver em sociedade quando têm o exemplo de seus responsáveis, o que exige a dedicação de tempo deles à sua educação. Garcia (1999) adverte que a indisciplina 
escolar, na contemporaneidade, é bem mais complexa e criativa, dando aos professores uma percepção de que não é tão fácil resolvê-la de modo afetivo.

É preciso, portanto, que haja uma sólida cooperação entre a escola e os responsáveis, considerando fundamentalmente o diálogo entre as partes, pois a escola sozinha nunca educará as crianças. Esse cenário permite que se visualizem as dificuldades que hoje a escola enfrenta para manter e fazer cumprir suas regras de conduta.

\section{Procedimentos metodológicos}

\section{O objeto de estudo}

Cabe, inicialmente, abordar o objeto do estudo avaliativo, que foram as Normas de Convivência aprovadas pelo Conselho Pedagógico do Colégio de Aplicação da Universidade Federal do Rio de Janeiro (CAp-UFRJ 2006). Tais normas são compostas de 20 artigos, mas os que foram submetidos à avaliação no presente estudo estão tratados no Título I - define o vestuário art. 1 e 2; no Título II - aborda o horário escolar - art. 3 ao 9; e no Título IV - discute as faltas disciplinares - art. 11 a 18.

Trata-se, pois, de uma Resolução bastante objetiva, com poucos artigos, elaborada para ser funcional.

\section{Objetivo, questões avaliativas e relevância do estudo}

O estudo teve como objetivo avaliar as Norma de Convivência Escolar do CAp-UFRJ, segundo o olhar de alunos do Ensino Médio. Para nortear o trabalho foram traçadas três questões avaliativas, respondidas ao final deste artigo, a saber: (a) em que medida as Normas de Convivência do CAp UFRJ atendem às necessidades dos alunos? (b) que sugestões são apresentadas pelos alunos para o aperfeiçoamento dessas normas? (c) até que ponto o cumprimento das Normas de Convivência do CAp UFRJ afeta o rendimento escolar dos alunos?

A sua relevância está no fato de que tais normas, ao se tornarem 
parte do cotidiano escolar (dezembro de 2006), nunca foram avaliadas. Passados mais de 10 anos, se torna imperiosa a sua avaliação tendo em vista que os alunos são outros e as mudanças na sociedade são tão rápidas que é provável que pensem de outro modo a respeito dessas normas.

Como se trata de assunto polêmico, que envolve a aplicação de penalidades, supôs-se que os resultados do estudo pudessem servir de subsídios àqueles que participam de decisões na gestão de uma escola de Ensino Médio. Ressalta-se, no entanto, que sendo o CAp - UFRJ uma escola muito específica, os resultados não podem ser estendidos a outro estabelecimento. Porém, na perspectiva de totalidade, o estudo pode servir de apoio a trabalhos a serem conduzidos em contextos similares.

\section{Abordagem avaliativa}

Da análise das diferentes abordagens, a escolha recaiu sobre a Abordagem Centrada nos Participantes, a qual abrange uma grande variedade de propostas, geralmente fundamentadas na filosofia intuicionista-pluralista ${ }^{3}$.

Esta abordagem surgiu em 1967 como consequência do descontentamento de teóricos da avaliação com as abordagens mecanicistas predominantes em estudos de avaliação educacional. Ela reagiu ao fato de que muitas avaliações de larga escala eram realizadas sem que os seus avaliadores fossem aos locais de sua implementação, para conhecer mais de perto o cenário educacional. Tais reações tomaram um grande vulto, clamando pela presença do elemento humano na complexidade da realidade cotidiana. A partir de 1970, a abordagem consolidou-se.

Os autores que conduzem esse tipo de abordagem preferem o uso de métodos de investigação naturalista, que buscam compreender as ações sociais no contexto de sua complexidade. Nesse tipo de abordagem está

\footnotetext{
${ }^{3}$ Esta filosofia se baseia na ideia de que o valor de algo sobre um sujeito depende do impacto do programa (da ação) sobre cada um, individualmente. As avaliações intuicionistas-pluralistas procuram envolver todos os 'juízes' afetados pelo programa que está sendo avaliado. Evitam deixar as decisões e os julgamentos a cargo de seus patrocinadores, como acontece no caso de avaliações utilitaristas. Tais avaliações tendem a seguir uma epistemologia subjetivista. (WORTHEN; SANDERS; FITZPATRICK, 2004, p. 110).
} 
previsto o envolvimento significativo daqueles que são participantes da atividade que está sendo avaliada. Assim, as abordagens centradas nos participantes desempenham uma importante função educativa. (WORTHEN, SANDERS E FITZPATRICK, 2004).

Entre as características dessa abordagem, segundo Worthen, Sanders e Fitzpatrick (2004), destacam-se: (a) o pesquisador utiliza o raciocínio indutivo - a compreensão do problema é feita no ambiente do programa; a compreensão não é um produto final, ela é descoberta antes da avaliação, (b) usa uma multiplicidade de informações, (c) não há um plano padronizado de avaliação, (d) os dados coletados representam múltiplas realidades; e (d) duas ações caracterizam a avaliação: a descrição e o julgamento. Como uma de suas premissas, situa-se a perspectiva de as 'verdades' serem construções sociais e a avaliação ser um processo interativo e de negociação entre os atores sociais. Ela apresenta limitações como o fato de não ser um modelo diretivo, podendo ocorrer o risco de não se concluir.

\section{Participantes do estudo}

Os participantes do estudo foram os alunos, integrantes das três turmas da segunda série do Ensino Médio, escolhidos de forma intencional. Retirou-se de cada turma os alunos mais antigos na escola, o que gerou um total de 41 alunos. Todos frequentavam o colégio desde o primeiro ano do Ensino Fundamental (7 alunos, repetentes, com ingresso no ano de 2007 e 34 alunos com ingresso em 2008), sendo 26 do sexo feminino e 15 do sexo masculino com idades entre 16 e 17 anos. Esse grupo constituiu o público do estudo, ao qual foram aplicados, em três dias, três questionários.

\section{Construção e validação dos instrumentos de coleta de dados}

A seleção de categorias e indicadores que subsidiam a construção do instrumento avaliativo é fundamental, pois são eles que garantem a transparência do ato de avaliar. Assim, recorreu-se à revisão da literatura sobre Uniformes fazendo um diálogo com as normas do CAp - UFRJ. 
Considerando as três categorias: Vestuário; Horário Escolar e Faltas Disciplinares, buscou-se subdividi-las em indicadores que estariam afetos a cada uma dessas categorias e seriam avaliados, conforme se apresenta no Quadro 1.

Quadro 1- Categorias avaliativas e seus indicadores

\begin{tabular}{|c|c|}
\hline $\begin{array}{l}\text { Categoria } \\
\text { Avaliativa }\end{array}$ & Indicadores \\
\hline Vestuário & $\begin{array}{l}\text { - Praticidade com o seu uso } \\
\text { - Valores inseridos no seu uso } \\
\text { - Identificação do grupo de estudantes } \\
\text { - Democracia com o seu uso } \\
\text { - Compatibilidade entre moda e uso do uniforme } \\
\text { - Controle dos atos dos alunos } \\
\text { - Uso do boné }\end{array}$ \\
\hline Horário Escolar & $\begin{array}{l}\text { - Entrada e saída da escola no horário } \\
\text { - Entrada na escola até } 7 \mathrm{~h} 50 \text { min. } \\
\text { - Aluno atrasado só entra no } 2^{\circ} \text { tempo } \\
\text { - Entrada justificada após } 7 \mathrm{~h} 50 \text { min. } \\
\text { - Os atrasados esperam para iniciar o } 2^{\circ} \text { tempo de } \\
\text { aula } \\
\text { - Os alunos com atraso devem ter seus nomes } \\
\text { encaminhados à DAE } \\
\text { - Não há tolerância para atraso às aulas } \\
\text { - Saída mais cedo da escola deve ser justificada } \\
\text { - A permanência na escola, após o término das } \\
\text { aulas, deve ser solicitada à DAE }\end{array}$ \\
\hline Faltas Disciplinares & $\begin{array}{l}\text { - Estar indevidamente uniformizado } \\
\text { - Chegar atrasado ou sair antecipadamente com } \\
\text { frequência } \\
\text { - Deixar de trazer o material escolar } \\
\text { - Deixar de realizar as tarefas escolares } \\
\text { - Ausentar-se da sala e do colégio sem autorização } \\
\text { - Ter atitudes inadequadas } \\
\text { - Usar o celular durante a aula } \\
\text { - Prejudicar andamento das atividades escolares } \\
\text { - Importunar os colegas } \\
\text { - Utilizar materiais sem prévia autorização nas } \\
\text { atividades desportivas ou culturais. } \\
\text { - Portar objetos que impliquem perigo } \\
\text { - Destruir objetos de terceiros } \\
\text { - Desacatar o servidor público }\end{array}$ \\
\hline
\end{tabular}


- Agredir física ou verbal membros da comunidade escolar

- Praticar brincadeiras abusivas com os colegas

- Adulterar ou falsificar documentos oficiais

- Furtar objetos

- Portar ou fazer uso de drogas

- Valer-se de procedimentos ilícitos nas atividades escolares

Fonte: As autoras (2018).

Para a coleta de dados, foi organizado um questionário, dividido em três partes, com questões semiestruturadas, cada um deles focalizando uma categoria avaliativa que faz parte das Normas de Convivência Escolar.

Segundo Elliot, Hildenbrand e Berenguer (2012, p. 27), os questionários constituem valioso instrumento de coleta de dados, mas dependem de conhecimentos técnicos de quem o elabora.

No primeiro questionário, relativo à categoria avaliativa Vestuário, para as perguntas cujas respostas recaíram sobre as opções sim ou não, foi solicitada a justificativa da escolha (questões de 1 a 7). Nessa parte, a análise foi quantitativa para as opções sim/não e qualitativa na parte em que os alunos se expressaram livremente. As demais perguntas, em número de quatro (8 a 11), foram do tipo abertas, recebendo, portanto, tratamento qualitativo.

O segundo questionário, dirigido à categoria Horário Escolar, foi composto por 10 perguntas. Nove delas solicitavam respostas que recaiam sobre as opções concordo/discordo, tendo sido pedido a justificativa da opção escolhida. A última pergunta foi do tipo aberta. Assim, todas receberam tratamento qualitativo.

Finalmente, o terceiro questionário, sobre as Faltas Disciplinares, englobou 19 questões, sendo solicitado ao aluno que justificasse as afirmativas com as quais não concordavam. Neste caso, somente as respostas com "discordo" receberam análise qualitativa. Na questão de número 20, o aluno teve o espaço livre para avaliar as Normas de Convivência. 
O questionário, com suas 41 indagações, foi, então, submetido aos processos de validação técnica e de conteúdo, realizado por dois especialistas com doutorado em educação os quais ofereceram sugestões e recomendações para o seu aperfeiçoamento, todas acatadas.

\section{Aplicação do instrumento}

O instrumento desdobrado foi aplicado em três dias e em tempos de aulas distintos, para evitar prejuízos acadêmicos.

As respostas positivas e negativas a cada item dos instrumentos foram computadas e organizadas em tabelas. Como o número total de respostas variou de 41 a 0 , o critério estabelecido para classificação das respostas incluiu dois níveis: alta concordância às normas - de 41 a 21 respostas afirmativas - e baixa concordância às normas - de 20 a 0 respostas afirmativas.

\section{Resultados do estudo}

Os resultados são analisados em três seções, cada uma delas referente à aplicação dos questionários. Cabe mencionar que as respostas dos alunos foram transcritas como haviam sido escritas.

\section{Avaliação das respostas sobre a categoria vestuário}

A categoria Vestuário foi avaliada por meio de sete indicadores e mais quatro questões abertas, nas quais os alunos tinham de avaliar os motivos da escola pedir o uso do uniforme, oferecer sugestões para a sua melhoria, e fazer uma avaliação geral em relação ao mesmo.

$\mathrm{Na}$ parte quantitativa dos sete indicadores que continham opções fechadas (sim / não), encontrou-se em todas as indagações, à exceção da última, um número positivo de respostas. Esses resultados são os seguintes: (a) praticidade do seu uso (36 sim); (b) valores inseridos no uniforme (28 sim); (c) identificação dos alunos (26 sim); (d) democratização (28 sim); (e) 
compatibilização moda e uniforme (32 sim); (f) controle dos atos dos alunos (25 sim); (g) uso do boné (34 não).

Desse modo, os alunos, em sua grande maioria (36), foram favoráveis ao uso do uniforme, uma vez que ele tem o poder de igualar, sem dividi-los, além de ser prático para vestirem. Registraram, também (28), que o uniforme os identifica como alunos do CAp, gerando uma padronização de valores que evita as hierarquizações e as desigualdades. Os 13 alunos que discordaram da presença de valores no uniforme consideram que o uniforme mascara as diferenças e condições sociais; quando muito, os identifica como alunos de uma "escola federal de esquerda".

Houve, também, os que sentem orgulho em pertencer ao CAp (26), afirmando que o uniforme é uma referência e oferece segurança. Em contrapartida, encontrou-se 15 alunos que não percebem qualquer identificação pelo uso do uniforme. Para eles a identidade estudantil é criada pelo próprio aluno e o uniforme serve apenas para forçar uma identidade que não existe. No entanto, 28 alunos consideraram que o uniforme promove força (se tornam aparentemente iguais) para exercerem a democracia na escola quando precisam criticar, reivindicar ou manifestar suas opiniões.

Ficou, portanto, evidente a presença de uma ambivalência nas falas desses alunos, pois ao mesmo tempo em que são favoráveis ao uso do uniforme (por ter poder de igualar e ser prático de usar) parece que é percebido como instrumento para reivindicar, criticar e se manifestar livremente.

Ainda neste primeiro questionário, quando indagados sobre o controle da escola em relação ao uso do uniforme, falaram da flexibilidade do CAp (o foco geralmente é a camisa), mostrando que é possível compatibilizar (32) a “"relação moda-uniforme”. Alguns, no entanto, chegaram a afirmar que há limites para se criar a moda. Disseram, também (25), que percebem que a escola se vale do uso do uniforme para controlar a conduta dos alunos. Alguns afirmaram que não é o uniforme que vai mudar o modo como agem, o 
que tem certo sentido, ao considerar-se que esses alunos são bastante críticos.

No que tange ao boné, a maior parte dos alunos (34) defendeu o seu uso, oferecendo vários argumentos, pois acreditam que ele serve para "amenizar o sentimento daqueles que não se sentem bem com o seu cabelo".

Ao final desse primeiro questionário ficou evidente que os alunos gostariam de participar das discussões sobre o uso do uniforme com a direção da escola. Algumas falas são a seguir transcritas para dar a dimensão das repostas dos alunos:

R2 - "Uma ótima maneira de igualar os alunos e é bem mais fácil de se arrumar".

R12 - "Além de prático, o uniforme contribui para o padrão entre os alunos".

R14 - "É uma forma de identificação e unificação para que haja menos desigualdade".

R5 - "O uniforme serve para esconder a desigualdade social no colégio".

R27 - "Uma roupa com um símbolo não diz nada".

R25 - "Colocar todos iguais, não é dar identidade e sim forçar uma igualdade que não existe”.

R19 - "Se é obrigado a usar uniforme isso não é democracia".

R1 -"Eu não acho que o uso do uniforme altere o comportamento dos alunos".

R12 - "Malha da blusa melhor, outra cor de blusa, gostaria que o emblema fosse maior (permitindo uma maior visualização da instituição), menos transparente, mais customizada deixando aparente a nossa essência”.

\section{Avaliação das respostas sobre a categoria horário escolar}

A categoria Horário Escolar foi avaliada por meio de 9 indicadores e mais uma questão aberta onde os alunos deviam fazer uma apreciação geral sobre o horário escolar. 
Na parte quantitativa dos dados observou-se que as repostas dadas a cinco itens tiveram alta concordância. Foram elas: (a) entrada e saída da escola no horário (39 concordo); (b) alunos atrasados só entram no $2^{\circ}$ tempo de aula (23 concordo); (c) alunos atrasados esperam em lugar específico para iniciar o $2^{\circ}$ tempo de aula (28 concordo); (d) alunos com atraso devem ter seus nomes encaminhados à DAE (32 concordo); (e) saída mais cedo deve ser justificada (30 concordo).

Os itens com baixa concordância foram (a) entrada na escola até 7h50min (33 discordo); (b) entrada na escola justificada após 7h50min (26 discordo); (c) falta de tolerância para atraso às aulas (34 discordo); e (d) permanência na escola após o término das aulas deve ser solicitada à DAE (40 discordo).

Observou-se muita discordância em relação ao tema. Eles não concordam com a entrada na escola até as 7 h e 50 minutos. Discordam, também, da necessidade de justificar a entrada após este horário, pois afirmam que moram longe e o trânsito é caótico, sendo impossível adivinhar o dia em que terão dificuldade para chegar na hora. Reclamaram da falta de tolerância com os atrasos e quase todos discordaram da necessidade de solicitar à DAE um pedido com antecedência para poderem permanecer na escola após o término das aulas.

Contraditoriamente, afirmaram que a escola deve ter um horário de entrada e saída e que os alunos que chegam atrasados devem esperar em um local, que seja adequado, para entrar na sala de aula no tempo seguinte. Concordam que os alunos que chegam atrasados devem ter seus nomes encaminhados à DAE para um acompanhamento e que a saída mais cedo da escola deve ser justificada. A maior parte dos que concordaram com as normas sobre o horário foram enfáticos ao afirmar que tais providências devem ser tomadas para evitar atrapalhar o andamento das aulas.

Verificou-se, também, uma capacidade de crítica por parte desses alunos, com apresentação de sugestões para resolver os impasses. A seguir estão algumas falas que oferecem a percepção sobre o horário escolar. 
R11 - "Pois se não tiver horário pode ficar bagunçado e o aluno vai entrar a hora que quiser. Não haverá um controle”.

R14 - "É importante para a organização da grade escolar e do planejamento das aulas".

R12 - "Com a grande quantidade de carros na rua, e imprevistos que ocorrem com todos nós, o horário de entrada poderia ser estendido".

R18 - "Entrar no meio da aula atrapalha a dinâmica do professor e dispersa os demais alunos".

R9 - "Se o professor permitir deverá ser liberada a entrada".

R10 - "Se um aluno se atrasa sempre, é importante saber o motivo".

\section{Avaliação das respostas relativas à categoria faltas disciplinares}

A categoria Faltas Disciplinares foi avaliada por meio de 19 indicadores e mais uma questão aberta, onde indicariam se o cumprimento das Normas de Convivência afetaria o rendimento escolar.

A Tabela 1 apresenta o quantitativo das escolhas que cada um desses indicadores recebeu.

Tabela 1 - Avaliação dos indicadores da categoria Faltas Disciplinares

\begin{tabular}{l|c|c}
\hline \multicolumn{1}{c|}{ Indicadores } & Concordo & Discordo \\
\hline 1. Estar indevidamente uniformizado & 17 & 24 \\
\hline $\begin{array}{l}\text { 2. Chegar atrasado ou sair antecipadamente com } \\
\text { frequência }\end{array}$ & 19 & 22 \\
\hline 3. Deixar de trazer o material escolar & 13 & 28 \\
\hline 4. Deixar de realizar as tarefas escolares & 16 & 25 \\
\hline 5. Ausentar-se da sala e do colégio sem autorização & 26 & 15 \\
\hline 6. Ter atitudes inadequadas & 38 & 3 \\
\hline 7. Usar o celular durante a aula & 24 & 17 \\
\hline 8. Prejudicar o andamento das atividades escolares & 40 & 1 \\
\hline 9. Importunar os colegas & 40 & 1 \\
\hline 10. Utilizar materiais sem prévia autorização & 26 & 15 \\
\hline nas atividades desportivas ou culturais & 38 & 3 \\
\hline 11. Portar objetos que impliquem perigo & & \\
\hline
\end{tabular}




\begin{tabular}{l|c|c}
\hline \hline 12. Destruir objetos de terceiros & 39 & 2 \\
\hline 13. Desacatar o servidor público & 41 & - \\
\hline $\begin{array}{l}\text { Agredir física ou verbal membros da } \\
\text { comunidade escolar }\end{array}$ & 36 & 5 \\
\hline $\begin{array}{l}\text { Praticar brincadeiras abusivas com os } \\
\text { colegas }\end{array}$ & 41 & - \\
\hline 16. Adulterar ou falsificar documentos oficiais & 41 & - \\
\hline 17. Furtar objetos & 41 & - \\
\hline $18 . \quad$ Portar ou fazer uso de drogas & 33 & 8 \\
\hline $\begin{array}{l}\text { Valer-se de procedimentos ilícitos nas } \\
\text { atividades escolares }\end{array}$ & 39 & 2 \\
\hline \hline
\end{tabular}

Fonte: As autoras (2018).

Na maior parte das perguntas (15 delas), os alunos expressaram alta concordância com as normas. Em alguns casos, como: praticar brincadeiras abusivas com os colegas, furtar objetos, adulterar ou falsificar documentos oficiais e desacatar o servidor público, esta adesão foi unânime.

Em outras situações, como: ausentar-se da sala de aula e do colégio sem autorização; ter atitudes inadequadas; usar o celular em sala de aula; usar objetos não autorizados nas aulas desportivas ou culturais; portar objetos que sejam perigosos; destruir objetos de terceiros; agredir física ou verbalmente membros da comunidade escolar; portar ou fazer uso de drogas; e valer-se de procedimentos ilícitos durante as atividades escolares, a adesão às normas foi significativa, pois oscilou de 24 aderentes a 39.

Cabe destacar que em quatro perguntas (deixar de trazer o material escolar; deixar de realizar as tarefas escolares; chegar atrasado sistematicamente; e estar indevidamente uniformizado), os alunos apresentaram baixa concordância com as normas. Alegaram que a responsabilidade é do aluno e não cabe a escola tomar conta desses itens.

Observou-se, então, que os alunos acham que é importante respeitar as atividades escolares para não atrapalhar o seu andamento, mas querem ter autonomia para decidir o que devem fazer.

Algumas respostas são a seguir transcritas para que se possa melhor 
compreender o ponto de vista dos alunos.

R39 - "Não vejo necessidade na fiscalização do uniforme de forma a penalizar uma vez que não se leva em consideração o contexto da situação".

R40 - "Somente quando houver uma justificativa mandada pelos pais".

R21 - "O aluno não pode entrar e/ou sair da escola no momento que ele bem entender".

$\mathrm{R} 10$ - "O aluno também tem problema, a escola raramente sabe da realidade de cada um".

R25 -“A relação do aluno com o próprio material é algo pessoal e de organização própria, não fazendo sentido punir, se é algo pessoal".

R38 - "Imprevistos podem acontecer! Estou no ensino médio".

R27 - "Às vezes os professores não entendem que os alunos são indivíduos que fazem outras coisas além de só estudar”.

R41 - "O aluno deve ir às aulas, caso ache que não precisa ouvir a aula é só dormir (sem desrespeitar o professor)".

R1- "Se uma pessoa (do nono ano pra cima) não quer assistir aula deixa ela não assistir, ela tem maturidade pra saber o que é melhor pra ela".

R10 - "Contando que não atrapalhe os colegas. Se ele usar [o celular] é decisão dele, deveria ser livre a escolha".

Por último, na questão 20, foi pedido aos alunos que avaliassem, se o cumprimento das Normas de Convivência afetaria seu rendimento escolar. Todos os 41 alunos expressaram sua opinião, encontrando-se quatro grupos de respostas: (a) 19 alunos disseram que as Normas de Convivência afetam positivamente seu rendimento escolar, pois ao cumprilas se sentem mais disciplinados e organizados; elas tornam o ambiente escolar mais harmonioso e agradável; (b) 11 alunos mencionaram a importância das Normas para um bom funcionamento da escola, colaborando para melhor integração e respeito no ambiente, mas afirmaram não serem afetados por elas; (c) 8 alunos afirmaram que são afetados 
negativamente pelo cumprimento das Normas de Convivência; (d) 3 alunos se sentem afetados por alguma norma, em especial, como horário (quando chegam atrasados), cobrança do uniforme e quando deixam de trazer o material escolar.

Para cada uma dessas posições, foi selecionada uma resposta como exemplo da avaliação dos respondentes.

R17 - "Me torna mais disciplinada e mais organizada para lidar com as situações da vida no futuro".

R11 - "As normas de convivência não afetam meu rendimento escolar. Concordo com grande parte das normas e acho justas. Também acho que algumas deveriam mudar um pouco, mas de forma geral, concordo com a maioria. Elas colaboram para uma melhor interação e respeito ao ambiente escolar".

R6 - "Eu não tenho pai e mãe para lavar e comprar uniforme; moro longe e dificilmente chego no horário; usar boné e celular deve ser responsabilidade minha, e não assistir aula deveria ser opcional e me sinto muito afetado e preocupado com o cumprimento dessas normas no meu rendimento escolar".

R8 - "Boa parte das normas são necessárias e não me afeta muito. Só afeta quando chego atrasado e acabo perdendo a aula”.

Esses resultados refletem aspectos da teoria. Eles sabem que o uniforme pertence à cultura do CAp, marcando este lugar nos alunos. Sentem a praticidade do seu uso, ao mesmo tempo, em que buscam criar inovações para comunicar a "essência individual". Percebem que a escola incute a ideia de democracia por meio do seu uso, fazendo, também o controle e a padronização dos alunos.

\section{Considerações finais}

Retomam-se aqui as questões avaliativas do estudo para respondê-las. A primeira questão: em que medida as Normas de Convivência do CAp UFRJ atendem às necessidades dos alunos, pôde ser respondida com a 
análise dos resultados oferecidos pelos alunos nos três questionários. Assim, no questionário 1, ficou evidente, pelo quantitativo geral das respostas e pelos registros dos alunos que a maior parte deles teve alta concordância com as normas. Apenas na última pergunta (sobre o boné), majoritariamente assinalaram a opção 'não concordo'.

No que tange às perguntas sobre o horário escolar (questionário 2), cinco das nove indagações foram respondidas pela maior parte dos alunos na opção 'concordo'. As demais (quatro) foram respondidas na opção 'não concordo'. Desse modo, pode-se dizer que o item horário escolar tendeu para atender às necessidades dos alunos, o que foi corroborado pelas falas registradas no questionário.

As indagações sobre as faltas disciplinares (questionário 3), teve 15 das 19 indagações respondidas positivamente ('concordo'). Apenas quatro perguntas foram marcadas em 'não concordo'.

Infere-se, então, que as normas atendem às necessidades dos alunos, pois em um total de 35 indagações apresentadas nos três questionários, a maior parte dos alunos assinalou a opção 'concordo' em 26 perguntas, o que representa um elevado grau de concordância $(0,74)$.

Todas essas inferências foram ratificadas pelos comentários livres dos alunos, emitidos, em seguida, a cada pergunta respondida.

A segunda questão avaliativa do estudo pedia aos alunos que apresentassem sugestões para o aperfeiçoamento dessas normas. Entre as diversas indicações sobressaiu o problema com a blusa do uniforme: a gola é muito próxima ao pescoço; o tecido é considerado ruim, pois é muito quente (provavelmente não é feita de puro algodão). Sugeriram, também, o nome do colégio escrito nas costas da camisa, o uso de chinelos como parte do uniforme oficial da escola. As meninas alegam que a liberação da regata minimizaria o calor. São problemas que os incomodam e merecem ser discutidos com vistas à melhoria do uniforme.

$\mathrm{Na}$ última questão avaliativa, que indagou sobre a interferência das normas no rendimento acadêmico, verificou-se que 30 alunos acham que que 
se beneficiam com as normas seja por que elas os ajuda a serem mais disciplinados nos estudos, seja por que contribuem para a harmonia do ambiente escolar.

Cabe finalmente dizer que esses respondentes se colocaram na posição de alunos da segunda série do Ensino Médio para responder aos questionários; portanto suas respostas não valem para os alunos de outros anos. Muitos deles possuem uma noção bem nítida de sua responsabilidade e, assim, reclamam de imposições determinadas pelas normas que cobram certos comportamentos para os quais eles, melhor do ninguém, sabem como devem agir. Assim, consideram que as normas deveriam ser mais flexíveis. Mostram-se preocupados com a parte pedagógica da escola - a aula -, defendendo-a radicalmente. As respostas apresentadas foram bastante coerentes e as reclamações, muitas delas, procedentes e devem ser repensadas pela escola. No computo geral, expressaram um sentimento de orgulho por pertencerem ao corpo discente do Colégio.

Oliveira e Müller (2018, p.13) afirmam que é fundamental a construção de normas por meio de uma parceria entre professores e alunos, para que haja uma boa convivência na escola. "A construção de normas e regras em conjunto favorece a criação de um clima de cidadania e a escola passa a ser vista como um espaço democrático e, ao mesmo tempo, um lugar de ensino". Para eles, "a escola não deve ser apenas um local agradável, mas polêmico, de conflitos, discussões e crescimento, onde o desejo dos alunos e suas necessidades represente os principais parâmetros para a elaboração de diretrizes que visem à organização da escola" (p.14). Assim, a escola estará contribuindo para construir a autonomia de pensamento e a reflexão que permitam a "conscientização da necessidade de respeitar as regras de convivência social, sem que sejam necessários a repressão e o uso de punições" (p. 14).

O estudo contribuiu para promover uma reflexão crítica sobre as normas de convivência, envolvendo alunos e professores, tendo em vista a função educativa que sustenta a Abordagem dos Participantes. 


\section{Referências}

AQUINO, J. G. (Org.). Indisciplina na escola: alternativas teóricas e práticas. São Paulo: Summus Editorial, 1996.

BERNSTEIN, B. A estruturação do discurso pedagógico: classe, códigos e controle. Vozes: Petrópolis, 1996.

BRASIL. Lei $\mathrm{n}^{\circ}$ 9.394, de 20 de dezembro de 1996. Estabelece as diretrizes e bases da Educação Nacional. Diário Oficial da União, Brasília, DF, 23 dez. 1996. Disponível em: <http://www2.senado.leg.br/bdsf/bitstream/handle/id/529732/lei_de_diretrizes_e_ba ses_1ed.pdf>. Acesso: 7 mar. 2018.

BORGES, L. O. A produção de identidade através dos uniformes escolares Significação e conceituação. Revista do Lhiste, Porto Alegre, v. 2, n. 3, p. 322-336, jul./dez. 2015.

CARVALHO, J. S. F. de. Os sentidos da (in)disciplina: regras e métodos como práticas sociais. In: AQUINO, J. G. (Org.) Indisciplina na escola/Alternativas teóricas e práticas. São Paulo: Summus, 1996, p. 129-138.

COLÉGIO DE APLICAÇÃO-UFRJ. UNIVERSIDADE FEDERAL DO RIO DE JANEIRO. Resolução do Conselho Pedagógico do Colégio de Aplicação da UFRJ. Resolução $n^{\circ}$ 03/06, de 12 de Dezembro de 2006. Normas de Convivência. 2006. Disponível em: <http://cap.ufrj.br/images/PDF/normasconvivencia.pdf>. Acesso em: 7 mar. 2018.

CORAZZA, S. M. O paradoxo do uniforme. Revista pedagógica, Porto Alegre, Artmed, ano 7, n. 28, nov. 2003/jan. 2004.

ECO, U. O hábito fala pelo monge. In: ECO, U. et al. Psicologia do vestir. 3. ed. Lisboa: Assírio e Alvim, 1989.

ELLIOT, L. G.; HILDENBRAND, L., BERENGER, M. M. Questionário. In: ELLIOT, L. G. (Org.). Instrumento de Avaliação e Pesquisa: caminhos para construção e validação. Rio de janeiro: Wak, 2012.

GARCIA, J. Indisciplina na escola: uma reflexão sobre a dimensão preventiva. Curitiba: Ipardes, 1999.

GARCIA, J. Indisciplina e violência nas escolas: algumas questões a considerar. Rev. Diálogo Educ., Curitiba, v. 9, n. 28, p. 511-523, set./dez. 2009.

LEITE, C. R. Convivência escolar: a questão dos conflitos entre alunos e professores e alunos. 2008. p. 2587-2598. Disponível em: $\leq$ http://educere.bruc.com.br/arquivo/pdf2008/127_136.pdf $>$. Acesso: 30 jan. 2018.

LONZA, F. História do uniforme escolar no Brasil. Brasília, DF: Ministério da 
Cultura, 2005.

MACEDO, L. de. Ensaios pedagógicos: como construir uma escola para todos? Porto Alegre: ARTMED, 2005.

NÓVOA, A. Os professores e o 'novo' espaço público da educação. In: TARDIFF, Maurice; LESSARD, C. (Org.). O ofício do professor: histórias, perspectivas e desafios internacionais. Petrópolis, RJ: Vozes, 2008.

OLIVEIRA, C. L.; MÜLLER, A. J. A indisciplina na escola: desafios e transformações. Educere et Educare, v 13, n. 29. Set/out, 2018, p.1-15.

SCHEMES, C.; SILVA; C. E. da; ARAUJO, D. C. de. A ressignificação do uniforme escolar na contemporaneidade: identidade e representação. Cadernos do Tempo Presente, Sergipe, n. 13, jul./set. p. 49-59, 2013. Disponível em: $<$ https://seer.ufs.br/index.php/tempo/article/view/2670> Acesso: 17 mar. 2018.

SILVA, K. N. da. Criança calçada, criança sadia! Sobre os uniformes escolares na escola pública paulista entre os anos de 1950 e 1970. Revista da Associação Brasileira de Estudos de Pesquisa em Moda, São Paulo, v. 1; n. 1; p. 74-81, out. 2007.

SILVA, K. N. da; CATANI, D. B. Fantasias da igualdade: uniformes escolares e democratização no Brasil. Cadernos de História da Educação, Uberlândia, v. 15, n. 2, p. 700-722, maio-ago. 2016.

WORTHEN, B. R.; SANDERS, J. L.; FITZPATRICK, J. R. Avaliação de programas: concepções e práticas. São Paulo: Ed. Gente, 2004.

Recebido em dezembro de 2018.

Aprovado em março de 2019. 